\title{
La vida cotidiana en el centro clandestino "Olimpo". Interacciones entre detenidos-desaparecidos
}

\author{
Daily life in the "Olimpo" illegal detention centre. The interactions between detainees
}

Florencia Cataldo Diaz

Universidad de Buenos Aires, Argentina

florencia.cataldo@hotmail.com

\section{Resumen:}

El trabajo aborda desde una nueva mirada el funcionamiento del centro clandestino de detención "Olimpo" entre agosto de 1978 y enero de 1979, durante la última dictadura argentina (1976-1983). Con tal fin analiza su dinámica cotidiana, a partir del análisis cualitativo de fuentes orales y escritas, enfocándose en las interacciones entre detenidos-desaparecidos y los elementos que las moldearon. Las principales conclusiones indican que aunque la desconfianza entre detenidos-desaparecidos subyació, primó el compañerismo; y que los lazos de socialización fueron el mecanismo de resistencia colectiva por excelencia, pues permitieron subsistir y restituir parte de la subjetividad arrebatada por el dispositivo represivo.

Palabras clave: Detenidos-desaparecidos, Represores, Olimpo, Vida cotidiana.

\section{Abstract:}

This study analyzes, from a new viewpoint, the way the "El Olimpo" illegal detention center operated between August, 1978 and January, 1979 during the last Argentine military coup (1976-1983). For such purpose, this study analyzes its daily dynamism, focusing on the interactions between detainees-disappeared people and the elements that shaped such interactions, based on a qualitative analysis of oral and written sources. The main conclusions point out that, although distrust among the detainees underlay, comradeship prevailed; and that socialization bonds were the main collective resistance mechanism, since they allowed the detainees to survive and restore part of the subjectivity grabbed by the repressive regime.

KEYWORDS: Detainees, Repressors, Olimpo, Daily life.

\section{INTRODUCCIÓN}

El centro clandestino de detención tortura y exterminio (CCDTyE) "El Olimpo" funcionó entre agosto de 1978 y enero de 1979, durante la última dictadura argentina; y se encontraba ubicado en el barrio porteño de Floresta, rodeado por viviendas y a una cuadra de la Avenida Rivadavia. Los grupos de tareas 1, 2 y 3 que operaron en él se encontraban bajo la órbita del Primer Cuerpo del Ejército, a cargo de Guillermo Suárez Mason; ${ }^{1}$ y dependían del Batallón de Inteligencia 601.

En este trabajo, que forma parte de una tesis de licenciatura, indagaremos las interacciones entre detenidosdesaparecidos surgidas a raíz de la estructura represiva montada sobre el "Olimpo". ¿En qué espacios y cómo surgieron? ¿Cuáles fueron sus particularidades y cómo fue su devenir? ¿Qué implicancias tuvieron en la dinámica represiva? A partir de estos interrogantes exploraremos si los detenidos-desaparecidos ante el horror del cautiverio mantuvieron vínculos oscilantes entre la contención y la solidaridad, y la desconfianza generalizada por temor a ser acusados por otros compañeros ante el personal represivo. También pondremos bajo estudio si la socialización entre detenidos-desaparecidos dentro del "Olimpo" representó el mayor mecanismo de resistencia por devolver parte de la humanidad arrebatada que les permitió sobrevivir. Para poner a prueba estas hipótesis consultaremos entrevistas de elaboración propia a ex-detenidos-desaparecidos,

Recibido: 12 de septiembre de 2019 | Aceptado: 05 de diciembre de 2019 | Publicado: 15 de enero de 2020

Cita sugerida: Cataldo Díaz, F. (2020). La vida cotidiana en el centro clandestino “Olimpo”. Interacciones entre detenidosdesaparecidos. Trabajos y Comunicaciones (51), e106. https://doi.org/10.24215/23468971e106 
el libro Desaparecido. Memorias de un Cautiverio escrito por Mario Villani (2011), legajos emitidos por la CONADEP, informes de organismos de Derechos Humanos, archivos audiovisuales del Juicio a las Juntas y del Juicio A.B.O I, ${ }^{2}$ y apuntes del juicio A.B.O III.

Cabe señalar que los testimoniantes cuyos relatos se analizarán pertenecen a grupos sociales, políticos y religiosos heterogéneos. Los mismos se encontraban en una franja etaria de veinticinco años promedio al momento del secuestro, y algunos fueron cautivos previamente en los CCDTyE "Club Atlético"3 y en el "Banco". ${ }^{4}$ Tenían ocupaciones variadas como estudiantes, psicólogos y obreros; y en su mayoría militaban en agrupaciones políticas de cuño peronista, aunque también de izquierda. La mayor parte son argentinos aunque otros son oriundos de Paraguay y de Bolivia. Si bien un alto porcentaje de los testimoniantes no eran creyentes, varios eran católicos o judíos.

Este trabajo está dividido en cuatro secciones. La primera delinea el estado del arte del tema en cuestión. La segunda esboza la distribución espacial del CCDTyE y su dinámica de funcionamiento. La tercera se sumerge en el estudio de los vínculos entre los detenidos-desaparecidos en el día a día, desde la mirada de los cautivos. Por último, la cuarta sintetiza las interacciones entre dichos actores en el momento en que éstos eran expulsados del centro.

\section{UN ESTADO DEL ARTE}

La preocupación por la historia de la vida cotidiana nace en la Argentina casi simultáneamente con el interés de las Ciencias Sociales por investigar el fenómeno dictatorial. Desde comienzos de la década de 1980, con la dictadura aún en el poder, se visualizan los primeros estudios que analizan el modo en que la represión estatal impactó en la cotidianeidad social. Un trabajo pionero es el de Juan Corradi (1996 [1982-83]), que estudia el terror como clave para entender la dictadura, y observa tempranamente que los grupos subordinados manifestaron una 'demanda primitiva' de orden, encontrado en el gobierno de facto. Poco después Guillermo O’ Donnell (1984) publica un artículo que discute algunos aspectos de la vida cotidiana argentina entre 1976 y 1980 . Entre finales de los 90 y los albores del nuevo milenio el problema del pasado dictatorial cobra impulso, dando lugar a trabajos que retoman los problemas planteados por obras clásicas de la historia de la vida cotidiana alemana durante el nazismo para pensar el caso argentino (Heller, 1987). En 2003 Marcos Novaro y Vicente Palermo (2003) elaboran una ambiciosa investigación sobre el impacto de la dictadura argentina en la vida cotidiana; construida a partir de una serie de entrevistas producidas en 1998 por estudiantes de la UBA, que son contrastadas con otras fuentes. Además irrumpen trabajos que indagan la vida cotidiana de las clases medias desde perspectivas novedosas, entre los que se destacan el de la comunicadora Mariana Caviglia (2006), centrado en el período dictatorial y el del sociólogo Sebastián Carassai (2013), que abarca ese tiempo incluyéndolo en una historia de más largo plazo. Si bien ambos son innovadores en sus preguntas, entienden a los testimonios como una vía transparente para acceder a las ideas que tienen los entrevistados sobre el pasado, desatendiendo a los elementos que permiten situar los testimonios como los datos biográficos de los entrevistados o el contexto de emisión. Algunos estudios recientes ofrecen perspectivas que rompen con la dicotomía de que las únicas opciones eran el apoyo o la resistencia a la dictadura; entre ellos el de Emmanuel Kahan (2011) sobre la experiencia judía durante la dictadura, y el de Eleonora Bretal (2016), que explora las visiones contrapuestas sobre el pasado dictatorial de trabajadores con pasados militantes en la izquierda y de aquellos que no tenían activismo político. Si bien este campo de estudios es aún incipiente en la Argentina, pues no se ha desarrollado una reflexión teórica sistemática ni una discusión pública del concepto de "vida cotidiana", existe un creciente interés en la comunidad académica (Lvovich, 2017).

A mediados de los 90 también comienzan a surgir investigaciones nucleadas en el funcionamiento de los CCDTyE durante la última dictadura argentina, que en algunos casos incorporan el análisis de la 
'cotidianeidad'. La politóloga y sobreviviente de la Escuela de Mecánica de la Armada (ESMA) Pilar Calveiro (1998) ofrece en 1998 el primer estudio global acerca de la lógica de funcionamiento de estos centros. La autora esgrime la figura de "campo de concentración" como expresión del poder desaparecedor que se articuló como hegemónico a partir de 1976; y señala que pese a sus pretensiones de poder totalizante, existieron 'líneas de fuga', es decir formas que encontraron los detenidos-desaparecidos de escaparse aunque no necesariamente de manera física; poniendo en jaque al poder que se creía omnipotente, impidiendo que la consumación de la deshumanización de las víctimas fuera lograda cabalmente. En una línea análoga a la de Calveiro, Gabriela Águila (2008) analiza la dimensión clandestina de la represión estatal global, pero desde un plano regional, poniendo foco en la organización de las fuerzas represivas y también en el microcosmos social de los campos clandestinos. Más allá de las particularidades regionales resulta un gran aporte, pues deja entrever cómo se repitieron una amplia gama de prácticas desarrolladas en otros campos clandestinos ubicados en otros espacios geográficos del país. Otra obra relevante es la de Andrés Di Tella (1999), que investiga la vida cotidiana en cautiverio a partir del análisis del caso de un ex-detenido-desaparecido en cinco CCDTyE (entre ellos el “Olimpo"): Mario Villani. Dicho trabajo contribuye al conocimiento más profundo de vivencias y sensaciones, si bien no resultan representativas de la cotidianeidad del encierro a nivel general. Con los ecos del vigésimo aniversario del Golpe de 1976, se edita el primer libro que reúne testimonios de cinco sobrevivientes de la ESMA (Actis, Aldini, Gardella, Lewin \& Tokar., 2001), fruto de exhaustivas jornadas de diálogo en un contexto de distención, que permitió ahondar en aspectos puntuales de las vivencias en cautiverio, que en algunos casos resultan impensadas a priori; y despierta una amplia gama de interrogantes sobre algunas facetas de la cotidianeidad en los centros; que amplía la óptica para explorar el objeto de estudio del presente trabajo.

Desde otro andamiaje académico-institucional el juez federal Daniel Rafecas (2005) expone en la resolución judicial de la causa 14.216/03 denominada "Circuito represivo A.B.O" una nueva matriz interpretativa para repensar los CCDTyE argentinos que desarticula la asociación centro clandestinolocalización geográfica, entendiendo que los predios del A.B.O constituyeron distintas denominaciones de un único CCDTyE por encontrarse bajo la órbita de la misma unidad militar y estar compuesta por los mismos grupos de tareas (Messina, 2008). Si bien esta perspectiva puede ser valiosa a los fines de la investigación judicial; para el análisis de carácter histórico que se pretende en este artículo resulta imperioso resaltar un puñado de factores que tamizaron la realidad de cada uno de estos centros: el período en que estuvieron en actividad, las personas allí detenidas y la coyuntura política que los atravesó; en pos de devolverles historicidad.

Con el inicio del nuevo milenio y el restablecimiento de los Juicios por delitos de Lesa Humanidad afloran estudios que iluminan dimensiones específicas del dispositivo represivo de los CCDTyE. Entre estos se destacan los vinculados a la perspectiva de género, que emergen con la principal finalidad de esclarecerlos delitos sexuales cometidos durante la última dictadura, silenciados durante décadas. Entre los trabajos más influyentes se encuentran el escrito por Balardini, Oberlin y Sobredo (2010), por Analía Aucía, Florencia Barrera, Celina Berterame, Susana Chiarotti, Alejandra Paolini, y Cristina Zurutuza (2011), los publicados por Santiago Garaño(2010) y Débora D' Antonio (2016a), y el editado por Memoria Abierta (Bacci, Capurro Robles, Oberti \& Skura, 2012); los cuales, desde diferentes abordajes, dan cuenta del ejercicio sistemático de la violencia sexual hacia mujeres en distintos ámbitos de encierro, que es catalogada como un delito diferenciado de otras clases de tormento. Estos estudios abonan nuestra investigación, pues demuestran que el género es determinante para comprender cabalmente los mecanismos represivos ejercidos por las fuerzas represivas, para desentramar las interacciones entre detenidos-desaparecidos y entender en qué medida las estrategias de resistencia que desarrollaron estuvieron atravesadas por su sexualidad.

Hacia 2010 también surgen nuevas producciones de ex-detenidos-desaparecidos, entre ellas la de Mario Villani (2011), que resulta un aporte sustantivo a este estudio tanto a nivel bibliográfico como documental pues permite sumergirnos en el desarrollo general del mundo clandestino y de la dinámica del "Olimpo" en 
particular, desde una experiencia singular. Además ilumina las sensaciones que lo atravesaron durante esa etapa y en los años posteriores a su liberación.

A fines de la década del 2000, con los ecos del desalojo de la Policía Federal Argentina (PFA) del predio del ex-CCDTyE “Olimpo" en 2005 y la consagración del sitio en como espacio de memoria, en cogestión entre el Estado Nacional y organismos de Derechos Humanos y sociales, irrumpen una serie de estudios que abordan al ex-"Olimpo". En primer lugar la historiadora Florencia Levín (2008) analiza la 'responsabilidad colectiva' de la última dictadura y de la memoria sobre el pasado, a partir de la exploración de testimonios de vecinos que habitaron durante la dictadura en barrios donde funcionaban CCDTyE, entre ellos el "Olimpo", aproximándose de manera tangencial al funcionamiento del "Olimpo" como centro clandestino.

En 2010 la antropóloga Luciana Messina (2010) publica el primer trabajo de tesis sobre el ex-"Olimpo", nucleado en torno a las formas en que se articulan las políticas y los lugares de memoria en los procesos de construcción de la memoria social sobre el terrorismo de Estado en la Argentina. En este sentido profundiza el trabajo de Ana Guglielmucci (2009), que examina las disputas y debates sociales y políticas previas y posteriores al proceso de transformación del predio en sitio de memoria. Por su parte Béatrice Fleury y Jacques Walter (2011) compilan un libro inscripto en la profusa producción internacional sobre sitios de memoria, que demuestra que los mismos son producto de las intervenciones de actores que los elaboran poniendo en juego sus perspectivas sobre el pasado, sus intereses y valores del presente y sus horizontes de futuro. Fleury examina el proceso de transformación de las relaciones entre un edificio y su entorno en actos, haciendo una suerte de analogía con el ex-Olimpo, en la que trae a cuento siguiendo a Messina, las reuniones entre representantes del Estado, Derechos Humanos y sociales, sobrevivientes y familiares de exdetenidos-desaparecidos, una vez que el Estado cedió el predio, para construir un proyecto de uso integral del sitio. A partir de 2012 aparecen una serie de trabajos elaborados por la Mesa de Trabajo y Consenso del ex-“Olimpo” (Mendizábal et. al., 2012; Mendizábal \& Portos, 2014). Estos estudios, que exceden el campo académico, abonan el campo de la memoria acerca del "Olimpo" y emergen como resultado de un puñado de encuestas realizadas por este equipo a vecinos que vivieron en el barrio de Floresta durante los años 1978- 1979 y a jóvenes que se mudaron allí con posterioridad; en el marco de los proyectos denominados "Recuperación de la Memoria Histórica sobre el ex-CCDTyE "Olimpo", y "Memorias de Vecindad”.

Lo dicho hasta aquí demuestra la existencia de un abanico de estudios acerca del "Olimpo" desde el campo de la memoria, que resultan esenciales tanto para comprender el proceso de transformación del sitio en objeto memorial; como para rescatar las memorias de los vecinos. Sin embargo vislumbramos que el campo de estudios en torno al "Olimpo" por fuera del ámbito memorial se encuentra en ciernes. Esto nos invita a ofrecer en el presente artículo una nueva perspectiva, ubicada en el período en el que el "Olimpo" funcionó como CCDTyE, centrada en las relaciones que se tejieron en torno a éste.

\section{DiSTRIBUCIÓN ESPACIAL Y DINÁMICA DE FUNCIONAMIENTO}

Dentro del "Olimpo" se encontraba el "pozo" (donde eran alojados los detenidos-desaparecidos) montado sobre un gran playón de estacionamiento acondicionado para su uso como CCDTyE (Instituto Espacio para la Memoria, Ex-CCDTyE 'Olimpo', 2012). Éste estaba compuesto por dos secciones de celdas o 'tubos': 'Incomunicados', que contaba con cinco tubos con ventanas tapiadas que daban a la calle y una sala de tortura o "quirófano"; y 'población', integrada por cuatro filas de celdas separadas por pasillos, baños y un lavadero. En otro sector estaba la cocina, la enfermería, el comedor, el taller de electrónica y la sala de inteligencia (CONADEP, 1984).

Desde la perspectiva del detenido se distinguen dos grupos de personal represivo. Uno compuesto por miembros de la PFA, Policía de la Provincia de Buenos Aires, Servicio Penitenciario Federal, Ejército y personal civil. En él estaban los encargados de ejecutar secuestros, manejar la información para orientar el "interrogatorio" y conducir a la patota a nuevos 'blancos'; y las jefaturas de guardia. El otro grupo estaba 
integrado por sub-oficiales de Gendarmería Nacional, y estaba dividido en: guardias internas, encargados de vigilar a los cautivos aunque no tenían poder de decisión sobre ellos; y las guardias externas ubicadas en el techo, armados como custodia (Informe Amnistía Internacional, 1979).

El 16 de agosto de 1978 los detenidos en el "Banco" fueron mudados al "Olimpo". Desde allí nuevas detenciones se fueron ejecutando. Cuando un secuestrado o "chupado" -según la jerga represiva- llegaba al centro era despojado, en medio de insultos y golpes, de su nombre y se le asignaba un código alfanumérico al que debía responder de allí en más, inaugurando el proceso de desaparición de la identidad. Seguido a ello era conducido al 'quirófano' para ser sometido a interrogatorio bajo tormento. Concluida esta ceremonia, tal como establecía la dinámica general de los centros analizada por Calveiro (1998), era nuevamente tabicado ${ }^{6}$ y alojado en un tubo, incorporándose a la "vida cotidiana" del centro, donde el tormento (tanto físico como psíquico) era el eje vertebral para instaurar el terror por parte de un poder que se pretendía 'total'. Resulta pertinente aclarar que el término "cotidiano" es utilizado en este trabajo para referir a aquello que era habitual dentro del CCDTyE pues, si bien la 'vida cotidiana' de cada detenido quedó suspendida desde el momento de su secuestro interrumpiéndose la temporalidad y toda referencia a su entorno; en la situación de excepcionalidad que permeó al centro también hubo ciertas pautas de funcionamiento sistemáticas y prácticas que se reprodujeron diariamente, o que fueron repetidas con asiduidad.

Muchos detenidos-desaparecidos fueron llevados a "población" mientras que otros fueron alojados temporaria o permanentemente en "incomunicados". En "población” los cautivos compartían celda con uno o dos compañeros; y pasaban la mayor parte del tiempo engrillados, tabicados, y encerrados. Si bien allí también tenían prohibida la comunicación con el mundo exterior, era un poco más permisivo que "incomunicados". La comida era la indispensable para mantenerlos con vida mientras el dispositivo represivo lo desease. Generalmente les era permitido ir al baño una vez por día -debiendo pedir permiso y ser acompañados- y ducharse día por medio.

Por otra parte los testimonios distinguen dos tipos de guardia: las "duras" en referencia a su crudeza y las 'buenas'. Esta combinación de guardias 'buenos' y 'malos', y la conjugación de violencia con un trato "humanitario", que estuvo presente en gran parte de los represores, resultó colosalmente dañina pues tal estrategia de desgaste pretendía vulnerar la confianza de los detenidos-desaparecidos y la voluntad de resistir a la política disciplinar del centro (D’ Antonio 2016b).

Alrededor de la lógica represiva los cautivos comenzaron a desplegar mecanismos de resistencia (individuales y colectivos) que generaron lo que Calveiro (1998) llama "líneas de fuga", explicado anteriormente. Entre ellas podemos distinguir las "resistencias explícitas", que supusieron una confrontación directa con el poder represivo; y las "resistencias solapadas" en tanto formas de subvertir el poder a espaldas del dominador, en línea similar a lo que James Scott (2004) define como un “Discurso oculto", una conducta fuera de escena que se manifiesta abiertamente pero 'disfrazada' a través de rumores, gestos, canciones, chistes, transformándose en un producto social. A diferencia de lo que propone Scott, dentro del "Olimpo" este comportamiento 'fuera de escena' se desarrolló paralelamente a otras modalidades de resistencia explícita, aunque estas últimas fueron menos frecuentes. De los testimonios se desprende que, entre las formas privilegiadas de 'resistencia solapada' individual se encuentra la adquisición de una "habilidad extraordinaria" para ver sin quitarse la venda, el afinamiento del oído y el olfato, permitiendo dar cuenta por ejemplo de que cuando se escuchaba determinada música estaban torturando a un compañero. En cuanto a la percepción del tiempo existen discrepancias. Mientras algunos sostienen la imposibilidad de ubicarse temporalmente, otros narran las estrategias individuales que esgrimieron para situarse. También los mecanismos de 'resistencia solapada' colectiva fueron contundentes. Volveremos sobre ello.

Por otro lado, en Mayo de 1978 el Mayor Guillermo Minicucci (jefe del "Banco" y luego del "Olimpo") creó una suerte de "staff" de detenidos-desaparecidos al estilo del que el Almirante Massera había hecho en la ESMA, al que denominó 'consejo'; compuesto por cautivos obligados a realizar trabajo esclavo dentro del centro en los rubros de: limpieza, mantenimiento, cocina, acción sicológica e inteligencia (Calveiro, 1998). 
Además había un cautivo que oficiaba de médico apodado "Caballo loco" y una detenida como enfermera. Pertenecer al "consejo" permitía circular con mayor libertad, una mejor alimentación y horarios más flexibles que permitieron afrontar el encierro desde una perspectiva muy distinta, aunque sin sustraerse del marco general del horror.

Quienes integraban el consejo eran detenidos-desaparecidos con cierta antigüedad, o con una destreza especial para cumplir con alguna tarea; a diferencia del "staff" que estaba compuesto por militantes de alto rango político y sus parientes. Además su composición -por contraste con el "staff" que estaba conformado por miembros "estables"- varió después de cada "traslado"7 ; y tampoco tuvo una estructura tan ambiciosa, ni un trasfondo político tan marcado.

El consejo tuvo una utilidad real para los perpetradores, pues permitió descargar sobre los cautivos tareas de mantenimiento y logística que hubieran significado un gran desgaste de personal y presupuesto. Pero además pretendía el quebrantamiento psíquico del detenido para generar colaboración y aumentar la desconfianza entre los cautivos.

Sobre esta estructura también se abrieron líneas de fuga. Varios cautivos vieron allí la posibilidad de prolongar su vida y abstraerse de la realidad. Los miembros del 'consejo' realizaban tareas manteniendo contacto unos con otros, forjando redes de contención que se extendieron incluso hacia los detenidosdesaparecidos "comunes" (aquellos que no tenían tareas asignadas dentro del centro), que serán desarrolladas en la siguiente sección. Pero sobre todo permitió sacar provecho de la cercanía con los captores y del acceso a información; mitigando la incertidumbre y devolviéndoles algo de la humanidad arrebatada. Pertenecer al consejo también significó vivir el horror más de cerca y sufrir el tormento que suponía contribuir con la reproducción del CCDTyE- al igual que les sucedió a los integrantes del "staff" (Calveiro, 1998). Sólo en casos excepcionales esta 'colaboración' se tradujo en la participación directa en la tortura, aunque no se rastrean casos comparables al de Máximo Nicoletti ${ }^{8}$, ni la existencia de un grupo similar al "ministaff" de la ESMA. De todas formas es necesario no perder de vista que estos comportamientos estuvieron atravesados por el accionar represivo, y que ningún cautivo estaba allí por voluntad propia.

\section{LOS VÍNCULOS ENTRE DETENIDOS-DESAPARECIDOS}

Comenzaremos analizando los vínculos que se tejieron entre los detenidos-desaparecidos "comunes" y los miembros del consejo; y luego exploraremos las relaciones entre detenidos-desaparecidos "comunes".

La posibilidad de entablar contacto entre cautivos dependió en primer lugar del sector en que se encontraban. Mientras que los alojados en "población" (incluyendo detenidos-desaparecidos "comunes" y del consejo) tuvieron la posibilidad de relacionarse, aquellos que permanecieron en "incomunicados" estuvieron prácticamente aislados; pues incluso los miembros del consejo tenían la entrada vedada. Son varios los relatos que marcan la diferencia sustancial entre estar solos día y noche, y el poder compartir su situación con otras personas. En este sentido el aislamiento representaba un mecanismo de tormento formidable. Sin embargo la reclusión total no fue posible: en el momento de ducharse lograban relacionarse con otros compañeros, aunque de manera efímera.

Si bien cualquier inmediación entre los cautivos era severamente castigada; éstas estuvieron presentes y se hicieron eco en el despliegue de múltiples lazos de contención y solidaridad. Estas interacciones supusieron en sí mismas un mecanismo de resistencia de carácter colectivo, pues fueron cimentadas entre dos o más cautivos. En muchos casos estuvieron permeadas por actos de lo que Tzvetan Todorov (1993) llama "virtudes cotidianas", es decir pequeñas acciones de valor que rechazan el dispositivo represivo en beneficio de una o varias personas muy próximas. Éstas no se practican de manera grandilocuente sino como parte de la cotidianeidad, por lo que pasan desapercibidas, salvo para quienes se ven beneficiados; y suelen caracterizarse por un nivel de riesgo alto para quien las ejecuta. Las mismas se dieron dentro del "Olimpo" en distintas 
formas como: intentar evitar sesiones de tortura o golpes a compañeros, contar un secreto, o hacer circular información.

La resistencia solapada se yuxtapuso con resistencias explícitas, como negarse a dar información durante la tortura o a desvestirse; pero todas tuvieron como correlato la aplicación de tortura. El suicidio fue el mecanismo de resistencia explícita en su máxima expresión, pues el detenido "Selló de manera definitiva la información que poseía un hombre, le arrebató al campo el derecho soberano de vida y muerte, y con ello debilitó su aparente omnipotencia" (Calveiro, 1998, p. 115).

Antes de sumergirnos en el estudio de las interacciones entre los detenidos-desaparecidos es necesario hacer una salvedad metodológica. En el acervo testimonial consultado se observa una diferencia fundamental entre los relatos emitidos en el marco del Juicio a las Juntas y los elaborados en el marco el reanudamiento de los juicios por delitos de lesa humanidad en sus diferentes formatos (jurídico y extra jurídico). En el primer caso las referencias a la existencia de vínculos entre los cautivos son excepcionales debido a que la finalidad del Juicio a las Juntas era probar la existencia de un plan sistemático de represión, tortura y exterminio, lo cual produjo un constante re-direccionamiento de las declaraciones por parte de jueces y fiscales para situar los relatos en aquello que permitiera incriminar a los acusados, produciendo testimonios acotados en tiempo y obturando cualquier comentario que se 'desviara' de tales propósitos. Pero también guarda una relación directa con el temor de los testigos a contar lo vivido ante el estrado judicial en el contexto de transición democrática, tamizada por la desconfianza en la pérdida de poder de las Fuerzas Armadas y por la emergencia de la teoría de los dos demonios, ante una sociedad asediada por los efectos del terror. Por otro lado la escasa mención de interacciones con otros detenidos-desaparecidos en estos relatos es para referir al 'colaboracionismo' de algunos de ellos. En cuanto a las declaraciones ante la CONADEP, allí se rastrean algunas referencias a vínculos entre compañeros, aunque el foco no está puesto en ese tema. Por el contrario los testimonios producidos durante la última década, en una democracia más consolidada y con desarrollo de procesos judiciales específicos de cada circuito represivo -llevados a cabo por jueces y fiscales con una mayor escucha- dieron lugar a relatos pormenorizados que remiten a lo que fue la vida cotidiana en el "Olimpo". Esto último se asemeja a lo expresado en las entrevistas.

\section{A. Vínculos entre detenidos-desaparecidos "comunes" y miembros del consejo}

Una vez ingresado al "Olimpo" el detenido era puesto en contacto con el personal represivo para interrogarlo bajo tortura y luego con algunos miembros del consejo. Son escasos los testimonios que refieren a la primera sensación, pero quienes lo hacen lo describen como la entrada en un cono de sombras donde la desorientación y la incertidumbre se entrelazaron con la desconfianza al ver a otros detenidos-desaparecidos cumpliendo tareas (como tomarles la historia política, o interrogarlos).

No obstante esta desconfianza se fue relativizando con el tiempo, junto con la emergencia de múltiples expresiones de solidaridad de los integrantes del consejo, que se hicieron presentes de diferentes maneras y espacios; las cuales desarrollaremos en los siguientes sub-apartados.

\section{- Protección fisica}

Múltiples testimonios recuperan los intentos de los miembros del consejo por resguardar la integridad física de los detenidos-desaparecidos a partir de pequeños actos de 'virtud cotidiana'. Entre los intentos por mejorar el bienestar de los compañeros algunos miembros del consejo llevaban a detenidos-desaparecidos al baño sin autorización, transgrediendo a las 'normas' del centro y arriesgando su vida, pues ser descubierto por los represores suponía ser sometido a tortura. Cuantiosos relatos ponen énfasis en el empeño de los integrantes del consejo encargados de preparar la comida por garantizar las raciones y (aunque con poco 
éxito) hacerla lo más sabrosa posible con los recursos por demás escasos que tenían. Otra de estas expresiones fueron los ensayos de las detenidas que se desempeñaban en la lavandería por seleccionar (dentro de las posibilidades) ropa para cada cautivo según su talle. Si bien la elección de la vestimenta traspasó el rol impuesto por los represores a estas mujeres de cubrir los cuerpos y no resultó una condición elemental para la subsistencia, supuso un mecanismo de resistencia solapada que permitió restituir algo de la subjetividad de la que habían sido despojados. Cabe resaltar además que esta tarea fue concedida únicamente a mujeres, pues siguiendo el estereotipo de roles de la sociedad patriarcal de la cultura occidental eran ellas quienes estaban habilitadas para hacerlo. También se visualiza el aprovechamiento de varios miembros del consejo de sus atribuciones para conseguir cigarrillos, y circunstancialmente alguna comida distinta.

Por otro lado se destacan los cuidados de la integridad física de los cautivos. Juan G., militante de Cristianos para la Liberación, secuestrado junto a su esposa y su hijo de siete meses al cual prácticamente no pudo ver durante su cautiverio, relata que en una oportunidad cuando él se encontraba en su tubo con la puerta abierta vio que un compañero pasaba llevando al bebé en brazos. Ante esa situación describe "me dio tanta bronca, tanta impotencia que me saqué la venda de los ojos (...) salí del tubo y le saqué el chico [hijo de Juan] de los brazos (...) lo apreté muy fuerte se tranquilizó. No seas estúpido me dice, si te llega a ver otro te van a fusilar" (Testimonio Juan G., 2010). ${ }^{\text {? }}$

En este pasaje se observa cómo el compañero además de cuidar al pequeño (mientras estuvo separado de sus padres) velaba por la vida de Juan, que en un instante de debilidad desatendió las consecuencias que tendría si era visto por algún represor.

Más allá de los múltiples intentos por mejorar las condiciones de detención de los cautivos "comunes", aquellos que resultaban más vulnerables como las siete embarazadas que pasaron por el Olimpo, los niños y bebés (varios testimonios indican que fueron entre diez y quince) y compañeros malheridos recibieron un cuidado diferencial. En este sentido Isabel F., secuestrada a los 23 años pasando previamente por el "Banco", y que cursó parte de su embarazo dentro del "Olimpo" señala que cuando Jorge (otro detenido) barría el CCDTyE cada mañana le traía azúcar, un pan duro y algo dulce que comía con desesperación. Es decir, ante la posibilidad de conseguir comida 'extra' era priorizada la alimentación de una embarazada, pese a que el hambre y la necesidad de ingerir una comida sabrosa acongojaban a la gran mayoría de los detenidosdesaparecidos. Situaciones como éstas son traídas a cuento por otros cautivos.

Sin embargo no todos estos actos de protección estuvieron libres de contradicciones. Uno de los momentos más polémicos fue la decisión sobre la muerte. Mario V., militante peronista y activista sindical que estuvo detenido por cuatro años (en el "Atlético" y el "Banco" antes de ser llevado al "Olimpo" y luego en Pozo de Quilmes y ESMA); alude a esta situación que lo atormentó durante todo el período en que integró el consejo, a partir de una experiencia concreta cuando -junto con otros miembros- le fue ordenado revivir a un compañero que había sido torturado:

“El resultado final de ambas opciones era igualmente espantoso (...) ¡ ¡revivirlo o dejarlo morir? Quienes intentábamos resucitarlo éramos todos sobrevivientes de la tortura que, de alguna forma, habíamos llegado a donde estábamos. ¿Tenía derecho a no darle a ese muchacho la misma oportunidad?" (Villani, 2011, p. 112).

La angustia que recorrió a Mario se hace carne en sus palabras. Ambas decisiones resultaban dramáticas. Revivir al compañero era sentido por Mario como una colaboración activa hacia el aparato represivo, ya que le daba posibilidades de seguir torturándolo; pero también representaba un mecanismo de resistencia, pues mientras permaneciera vivo tenía chances de ser liberado. Por otro lado dejarlo morir era una forma de resistencia explícita, al desacatar la orden; pero anulaba definitivamente la vida del compañero. Mario y sus compañeros continuaron intentando salvar su vida mediante la respiración artificial. Finalmente falleció. 


\section{- El contacto verbal: entre el consuelo, el humor y la complicidad}

Además de las acciones para proteger físicamente a los detenidos-desaparecidos "comunes", el contacto verbal tuvo una nodal importancia. Al poder circular destabicados y visitar los tubos (para llevarles la comida a los cautivos y ver si necesitaban atención médica), los integrantes del consejo establecieron contacto directo con éstos, siempre dependiendo de la empatía y la predisposición para relacionarse en cada caso. El simple hecho de preguntarles cómo estaban o si necesitaban algo que pudieran facilitarles, significó aminorar el terror; y fue una fuente vital de supervivencia. En este sentido las 'pequeñas grandes cosas', esas virtudes cotidianas, tuvieron una importancia inconmensurable. Incluso algunos detenidos-desaparecidos que tuvieron una relación distante con los compañeros manifiestan la solidaridad de los integrantes del consejo. Porfirio F., militante de la Federación Juvenil Comunista, de nacionalidad paraguaya, reconoce haber estado prácticamente aislado de sus compañeros durante su cautiverio, a excepción del contacto con Santiago V. que era encargado de llevarlo al baño, a quien cataloga como "un pibe muy solidario" (Testimonio Porfirio F., ABO I, 2010).

Las palabras de aliento también fueron esenciales para calmar la desesperación que los abrumaba. Aunque en el afán por resguardar la salud psíquica de los compañeros, en ocasiones, lindaron con el ocultamiento de las verdaderas sospechas. Juan, que se encontraba muy preocupado por la salud de Mónica -su compañera embarazada y detenida junto a él- que había sido golpeada y picaneada; decidió preguntarle al 'médico' si eso tenía un efecto sobre el bebé. A lo cual le respondió: “"no, quedate tranquilo' (...) todo va a estar bien”' (Testimonio Juan G., 2010). Ante el abatimiento de Juan, el 'médico' intentó serenarlo con palabras tranquilizadoras y sobre todo esperanzadoras. Pero ¿Realmente creía que ello no tendría secuelas para el bebé en camino? Podríamos deducir que la negativa a aludir a las posibles consecuencias que podía sufrir la criatura formó parte de un mecanismo de salvaguardia del detenido. Después de todo ¿Qué podía haber hecho para evitar los efectos de una tortura ya consumada? Finalmente Mónica perdió su embarazo.

Por otra parte la transmisión de la información que recibían los miembros del consejo (sobre quiénes serían 'liberados' o 'trasladados', o de conflictos internos entre las fuerzas represivas) hacia los "comunes" resultó clave para enterarse de lo que ocurría en el centro. Sin embargo son notorias las diferencias existentes en el caudal de información de los relatos de los ex-detenidos-desaparecidos que entablaron vínculos con compañeros dentro del "Olimpo", y de quienes se relacionaron de manera ocasional tanto por aprensión como por temor. Además estos contactos fueron aprovechados para intercambiar experiencias de lo que estaban viviendo.

La transferencia de alegría y humor fue otro de los lazos de unión entre los detenidos-desaparecidos del consejo y los "comunes", que fueron esenciales para preservar la integridad psíquica de ambos grupos. Cantos, chistes, trucos de magia y mensajes subliminales combinados con sarcasmo fueron algunas de los modos en que la alegría logró inmiscuirse en las grietas de un submundo regido por el horror. Aquí se destacan las obras de teatro, escritas y actuadas por los detenidos-desaparecidos. Si bien éstas eran autorizadas por los captores (quienes además presenciaban la dramatización) fueron un espacio donde se hicieron eco la alegría y la complicidad y donde se caricaturizaba a la vida dentro del "Olimpo". Isabel, militante de la Juventud Universitaria Peronista (JUP), secuestrada a los 24 años en el "Banco" y luego mudada al "Olimpo", expresa con orgullo que durante las obras de teatro los detenidos-desaparecidos que actuaban "a veces decían cosas subliminales, que todos entendíamos y que por ahí los represores no" (Entrevista personal a Isabel C., 27/9/2016). Aquí se vislumbra además la existencia de un 'código tácito' entre los cautivos que los nucleaba, generando un espíritu de unidad por fuera de los represores. Sin embargo no era extraño que finalizada la obra hubiera reprimendas. 


\section{- La desconfianza latente}

Pese a la multiplicidad de vínculos erigidos entre los miembros del consejo y los detenidos-desaparecidos "comunes", la desconfianza hacia los primeros no desapareció por completo pues muchos continuaron percibiendo colaboración activa por parte de algunos miembros, especialmente en el sector de inteligencia o enfermería. En este sentido el rótulo de 'traición' se inscribe en un campo de disputa más amplio acerca de la categoría de 'víctima', entendida como un "concepto de combate", pues más allá de la existencia de un consenso básico sobre la noción de víctima, sus fronteras "son debatidas, reformuladas y cuestionadas en la Argentina contemporánea, impugnando su grado de universalidad y sus límites. Diferentes actores y grupos disputan su legitimidad a través de la producción de una verdad, cuya imposición no es más que una de las existencias posibles del grupo" (Vecchioli, 2013, p. 23). Horacio C. y Oscar G. fueron dos de los miembros etiquetados de esta manera por haber sido vistos por varios testigos y en diferentes momentos participando de la tortura, por lo cual la desconfianza hacia ellos se mantuvo e incluso se incrementó. Por el contrario la percepción de los cautivos acerca del vínculo entre "Caballo loco" y los cautivos "comunes" se tornó más ambigua, pues si bien controlaba el estado de salud de los cautivos mientras eran torturados, en oportunidades logró evitar que a aquellos deteriorados por la tortura los llevasen al Hospital Militar (pues ninguno de los que eran allí enviados regresaban). Esta confluencia de sensaciones se reiteró en otras ocasiones, como cuando algunos detenidos-desaparecidos se descompensaban en la tortura y eran reanimados por el 'médico'.

\section{B. Los vínculos entre detenidos-desaparecidos “comunes”}

Más allá relacionarse con el consejo, los detenidos-desaparecidos “comunes" también tendieron puentes entre sí. Nuevamente el baño fue el lugar de interacción por antonomasia entre cautivos alojados en distintos sectores, dado que era el único lugar al que todos concurrían y estaban destabicados. Si bien allí tampoco estaban libres del control de los represores, el hecho de ser varias personas que debían ser vigiladas al mismo tiempo y el ruido del agua posibilitaron mantener algún diálogo. En este sentido el baño representó uno de los puntos de fuga más notorios del modelo panóptico que analizó Michel Foucault (2007), en tanto estructura que permite al guardián desde una 'torre' central observar a todos los detenidosdesaparecidos recluidos en celdas individuales alrededor, sin que éstos puedan saber si son observados. Otro de los sitios donde se entablaron relaciones (entre detenidos-desaparecidos en tubos cercanos) fueron las puertas de las celdas. En ocasiones los guardias les permitían permanecer con la puerta abierta y salir al pasillo. Estos encuentros incluyeron intercambios que podemos sintetizar en: la protección, la solidaridad y la incorporación del humor y la alegría; aunque tuvieron expresiones diferentes que los impulsados por los miembros del consejo. Exploraremos cada uno de ellos. Pero cabe preguntarse ¿Los guardias no se daban cuenta de los diálogos entre cautivos en estas instancias? ¿Estaban implícitamente 'aceptados'? De ser así podríamos inferir que fue una estrategia para mantenerlos con vida hasta que el dispositivo represivo lo desease.

\section{- Las redes de protección}

Los vínculos entre detenidos-desaparecidos "comunes" se iniciaron una vez alojados en los tubos, tanto entre quienes se conocían de antemano como entre los que lo hicieron en la vorágine del cautiverio. N.F ${ }^{10}$, militante de Montoneros de 23 años, quien relató por primera vez su experiencia durante la entrevista realizada para esta investigación señala que en las duchas:

"Había chicas, chicas de 12 años, 13 con toda la furia, y lloraban (...) gritaban como chanchos, porque no sabían qué pasaba. Eran de la Acción Católica que trabajaban en las villas. Y claro, estaban desesperadas ahí porque era el momento que las 
habían puesto en la ducha a bañar. Y nosotras, las que más o menos algo sabíamos, las calmábamos" (Entrevista personal a N.F, 21/03/2017).

N.F. muestra como a pesar de estar también ella y sus compañeras en una situación adversa, decidieron tomar una actitud protectora hacia quienes se encontraban más indefensas aún, por su edad pero sobre todo por el absoluto desconocimiento de lo que significaba la prisión política.

La necesidad de brindar apoyo a sus semejantes es iluminada en diversos testimonios. Como vimos los diálogos tuvieron un rol protagónico para ofrecer palabras tranquilizadoras, pero también para transmitir la información que iban recolectando de experiencias particulares y ajenas. Ello deja entrever cierta complicidad entre los detenidos-desaparecidos para torcer el dispositivo represivo, obturando su pretensión de 'totalidad'. En este sentido Isabel C. señala

"Los primeros días son terribles, luego con el paso del tiempo (...) uno va conociendo el funcionamiento, y va hablando con los compañeros y vas en la medida de lo posible intercambiando algunas ideas (...) Yo lo que recuerdo y sentí siempre... que nos cuidábamos muchísimo de no dañar al otro (...) mantener la esperanza y si alguien veía algo cruel y que había ocurrido no se lo contaba al resto de los compañeros" (Entrevista personal a Isabel C., 27/9/2016).

El conocimiento de la dinámica del centro como resultado de la comunicación con los compañeros es rescatado por Isabel como el elemento que disminuyó su temor. Sin embargo pone énfasis en que (al igual que ocurría con los miembros el consejo) únicamente transmitían noticias que generaban alguna expectativa de supervivencia, pues entre sus propósitos estaba darse fuerzas, trenzando una red de contención mutua. Aquí se vislumbra nuevamente la delgada línea existente entre la protección y el ocultamiento.

Los lazos de protección entre los detenidos-desaparecidos "comunes" se extremaban hacia compañeros con mayor fragilidad, al igual que entre los miembros del consejo. Resulta pertinente señalar que el trato especial hacia las embarazadas fue efectuado con más frecuencia por otras mujeres, a través de charlas de la vida, de palabras de aliento y optimismo, y hasta conversaciones que planificaban un futuro de libertad cuando naciera el bebé. En cuanto a los compañeros brutalmente dañados, también se generó una red de sujeción especial, en pos de preservar su integridad física y sobre todo psíquica. Además el padecimiento de quienes eran torturados penetraba en el resto de los detenidos-desaparecidos; y generaba cierta empatía por sentirse pares y que cualquiera de ellos podría encontrarse en su lugar. Sin embargo a diferencia de lo que ocurría en la prisión política en cárceles comunes, los cautivos "comunes" no contaban con ninguna medicación para ofrecer. Estas redes de contención se pusieron en práctica en múltiples situaciones, especialmente con varios detenidos-desaparecidos practicantes de la religión judía, quienes por esta condición recibieron un trato aún más cruento que los demás cautivos. Isabel C. recuerda la protección que le otorgaron a Cristina C.:

\footnotetext{
“Se iba de la celda (...) y decía 'me voy, me voy' (...) y los compañeros que estaban en las celdas trataban de agarrarla porque sabían que la guardia que estaba ahí la iba a agarrar y le iba a pegar (...) ella no hablaba coherentemente porque prácticamente no hablaba con nadie, solamente decía esto, o lloraba o decía 'me voy' y entonces yo le decía 'Chile te queremos mucho', cositas así, y se puso a llorar, y lo único que decía era 'quiero ir con mi mamá' (...) yo, me senté con ella y era tan chiquita, se me acurrucó... y bueno se durmió en brazos” (Entrevista personal a Isabel C., 27/9/2016).
}

El caso de Cristina es uno de los únicos que se registra de detenidos-desaparecidos ultrajados psíquicamente, sin embargo muestra el alcance de estos vínculos. También es importante resaltar que el quebrantamiento psíquico se dio en una detenida que casi no mantenía contacto con sus pares. En el pasaje se visualiza como ante la extenuación de Cristina, que a su vez la volvía más susceptible de volver a ser torturada por infringir las 'normas' del centro; sus compañeros trataron de protegerla a través del diálogo y el afecto, pero también salvaguardando su cuerpo. 


\section{- Los lazos de solidaridad}

Entre las distintas expresiones de solidaridad podemos distinguir el compartir objetos que circunstancialmente algún detenido lograba conseguir. Ello ocurría por ejemplo cuando los represores permitían a algunos cautivos - por razones desconocidas- visitar a sus familias, quienes les preparaban cajas con alimentos y elementos de higiene para que se llevaran. O cuando algún represor regalaba a un detenido una ración de comida distinta de la habitual por cumplir una tarea excepcional; que resultaba satisfactorio dado el hambre que los agobiaba. En los testimonios se observa cómo poder comer una comida más sabrosa o conseguir un elemento de higiene era tan satisfactorio como compartir esa 'alegría' con sus pares, lo cual reafirma la fraternidad entre éstos.

Otro mecanismo de solidaridad para la comunicación de noticias resaltado por varios testimoniantes fue la idea de un detenido de tomar trozos de diarios que se encontraban en las letrinas a modo de papel higiénico

"¿Qué hacía este compañero? Sacaba el cachito de diario y se lo daba a otro cuando pasaba, se lo daba a otro que estaba en la celda y él armaba como el diario. Con ese, con esos cachos de recorte nosotros o algunos podíamos saber qué estaba pasando afuera (...) él se arriesgaba para que pudiéramos tener un cierto acercamiento a la realidad" (Entrevista personal a Isabel C., 27/9/2016).

La prisión clandestina no logró ocluir completamente el contacto con la realidad política externa al centro. Pequeños recortes de periódicos, junto con el ingenio de algunos cautivos fueron suficientes para implementar esta forma de resistencia solapada colectiva, sugestiva y provocadora; como resultado de una cuidadosa división de tareas. El riesgo que tomaron en pos de mitigar la desorientación de varios de los detenidos-desaparecidos y a la vez de quebrantar el poder 'total', también es recuperado por Isabel en tanto rasgo de virtud cotidiana.

\section{- Los juegos y el humor como estrategias de subsistencia}

La inclusión de los juegos y chistes, al igual que entre los miembros del consejo, fue otra expresión del vínculo entre cautivos "comunes" para traer algo de alegría. Entre las actividades lúdicas se encuentran las partidas de ajedrez y en menor medida el dominó o las cartas. Durante los instantes en que los guardias dejaban a los cautivos salir al pasillo también tenían permitido practicar estos juegos, cuyas fichas eran creadas con elementos precarios como migas de pan.

Los cantos fueron otro instrumento reparador. Isabel C. recuerda: "él [otro detenido] cantaba, venía a hacerle como serenatas a Claudia [una cautiva] y cantaba una canción y yo me puse a llorar, cantaba 'Carta para Julia' (...) Entonces me emocioné mucho y la cantamos juntos” (Entrevista personal a Isabel C., 27/9/2016). A pesar del infierno que estaban viviendo, las expresiones de vida como el cantar y el enamoramiento afloraron. Así la emoción que desbordó a Isabel al escuchar una canción familiar, interpretada por 'uno de los suyos' en un espacio tan adverso, la emocionó al punto de hacerla llorar. A su vez la posibilidad de cantarla juntos, para otra compañera, también denota la construcción de un lazo de hermandad. Pero los cantos también se dieron en otras oportunidades. Isabel C. cuenta la iniciativa de Marisa, una detenida que provenía de Cristianos para la Liberación, que quiso enseñarles villancicos para Navidad, a sabiendas de que la mayoría de sus compañeros eran ateos. Pero Isabel C. reconoce que lo que en verdad quería Marisa era cantar todos juntos y desparramar optimismo entre sus compañeros.

Pese a las múltiples muestras de compañerismo que tornaron el cautiverio un poco más llevadero, la desconfianza entre de detenidos-desaparecidos “comunes" tampoco fue desterrada por completo. Si bien el tiempo y los acontecimientos llevaron a muchos cautivos a tender redes de sociabilidad como un mecanismo tanto de resistencia como de subsistencia; la desconfianza 'mutua' subyació y trascendió el temor a la delación, pues aún sin quererlo el efecto de la tortura podía llevar a dar información sobre otro detenido. En este sentido 
la oralidad adquirió un rol secundario en la generación de credibilidad entre los detenidos-desaparecidos, cobrando protagonismo los gestos, las miradas, entre otras expresiones corporales, que resultaron más 'transparentes'.

Lo explayado hasta aquí permite afirmar que tanto los vínculos preexistentes como los que se construyeron dentro del "Olimpo" fueron un sostén moral inigualable para gran parte de los cautivos y una clave de supervivencia.

\section{INTERACCIONES DURANTE EL 'TRASLADO' Y LA 'LIBERACIÓN'}

Luego de un período de tiempo en que los detenidos-desaparecidos permanecían en el "Olimpo", las fuerzas represivas se deshacían de ellos. En varios casos fueron 'liberados ${ }^{\text {'1 }}$, pero el destino de la mayoría fue el 'traslado', que en la jerga represiva significaba el exterminio. ${ }^{12}$ Los instantes de la 'liberación' y en cierta medida el del 'traslado', fueron vividos con una rara combinación de entusiasmo, temor y perplejidad por quienes se iban pensando en un futuro cercano mejor. Pero también fue recorrido con cierta alegría por quienes continuaban cautivos pues representaba el fin de la tortura para sus compañeros y una esperanza de correr con la misma suerte.

En el instante en que los cautivos se enteraban de que uno de ellos saldría en libertad, le daban teléfonos y direcciones para llevara noticias a las familias. Incluso hubo cautivos prontos a salir que preguntaban a sus compañeros si querían que les llevaran algo, lo cual reafirma la fraternidad entre éstos. No obstante algunos de quienes continuaban cautivos sospechaban o sabían que no saldrían con vida de allí y emplearon el momento de la despedida para comunicárselo a sus amigos. Resulta llamativo que los represores les permitieran despedirse de sus compañeros, aunque podemos inferir que esto no fue más que otro mecanismo del aparato represivo para aumentar el desgaste, como sostienen algunos testimoniantes, o un método de tormento para los que 'liberaban', pues profundizaba el sentimiento de 'culpa' por dejar a sus compañeros.

Pero ¿La "liberación” significó en todos los casos el fin de estos lazos de afecto? Si no se extinguieron ¿De qué manera se reinventaron? Los testimonios no refieren en gran medida a los reencuentros o al contacto con los compañeros liberados. No obstante los que lo hacen dan cuenta de que estos vínculos surgidos en una situación límite, que los ayudó a transitar momentos terroríficos, trascendieron las paredes del CCDTyE. Éstos se tornaron indirectos debido a que los detenidos-liberados no tenían permitido establecer contacto con los cautivos. En los casos en que continuó habiendo algún vínculo, estuvo mediatizado por los represores a lo largo del período de control ilegal de los detenidos-liberados que aquí denominaremos "vigilancia atenuada". ${ }^{13}$ Allí hubo quienes explicitaban a los captores su necesidad de mejorar el pasar de los detenidosdesaparecidos e incluso algunos lograron hacerles llegar alimentos, arriesgando su propia vida. Pero además estas relaciones fueron indirectas porque la solidaridad de los que fueron 'liberados' se expresó a través del contacto con las familias de quienes permanecían detenidos.

Por otro lado, luego del retorno de la democracia -especialmente con el inicio de los procesos judiciales durante el gobierno de Raúl Alfonsín, reanudados durante la presidencia de Néstor Kirchner- hubo un reacomodamiento en estas relaciones. Durante este período se estrecharon los vínculos entre ex-detenidosdesaparecidos y familiares de detenidos-desaparecidos, en pos de reconstruir la historia y los derroteros de los desaparecidos. También hubo un restablecimiento progresivo de los lazos entre ex-detenidosdesaparecidos, como consecuencia de los juicios y de la fundación y la militancia en distintos organismos de Derechos Humanos entre ellos la "Asociación de Ex-Detenidos Desaparecidos" (1984), y la "Mesa de Trabajo y Consenso del Ex-Centro de Detención, Tortura y Exterminio 'Olimpo” creada por ex-detenidosdesaparecidos del centro entre los años 90 y el 2005, con los objetivos de denunciar los delitos cometidos por la última dictadura, brindar apoyo a los familiares de víctimas y exigir memoria, verdad y justicia. Son varios los relatos que -en distintos contextos temporo-espaciales- aluden a la restitución de los vínculos a 
raíz de reuniones en el marco de estos espacios que llevaron a emprender reflexiones sobre sus experiencias, establecer conexiones entre los distintos relatos y brindarse contención.

\section{Conclusión}

En este trabajo exploramos los modos en que se gestaron los vínculos entre cautivos en los intersticios del aparato represivo del "Olimpo". Tanto el diálogo entre detenidos como la circulación de información, cuyos espacios privilegiados fueron las duchas y los pasillos de las celdas, tuvieron un rol preponderante en el establecimiento de estos vínculos. A partir de ellos se tejieron redes de contención mutua, tanto entre los "miembros del consejo" como entre "comunes", que en muchos casos perduraron en el tiempo. Esto fue en cierta medida similar a la "contracultura carcelaria" desplegada por los presos políticos en el penal de Rawson (D’ Antonio, 2016b); aunque a diferencia de ésta, las redes de solidaridad tendidas dentro del "Olimpo" no tuvieron una organización tan clara ni una vinculación directa con la coyuntura histórico-política.

Si bien la aprensión y la desconfianza hacia los compañeros subyacieron en todo momento, la mayoría de los relatos ponen énfasis en el sentimiento de compañerismo que los unió, ubicando en un segundo plano las asperezas que existieron con algunos detenidos-desaparecidos. También el estudio realizado demuestra que los lazos de socialización fraguados al interior del "Olimpo" resultaron un mecanismo de resistencia colectiva en su máxima expresión, pues el sólo hecho de establecer algún tipo de contacto conculcaba las normas establecidas por el dispositivo represivo. Pero además estos vínculos tuvieron un rol esencial en la subsistencia de los secuestrados y para evitar un mayor deterioro de su salud mental, pues lograron devolver algo de la subjetivación que intentó ser eliminada de cuajo por el poder clandestino, que se evidenció en las múltiples expresiones de vida que traspasaron las fronteras del poder que se creía 'total'.

\section{REFERENCIAS:}

Actis, M., Aldini C., Gardella, L., Lewin, M. \& Tokar, E. (2001). Ese infierno. Conversaciones de cinco mujeres sobrevivientes de la ESMA. Buenos Aires: Sudamericana.

Águila, G. (2008). Dictadura, represión y sociedad en Rosario (1976/1983). Un estudio sobre la represión y los comportamientos y actitudes sociales en dictadura. Buenos Aires: Prometeo Libros.

Aucía, A.; Barrera, F.; Berterame, C., Chiarotti, S., Paolini, A.\& Zurutuza, C. (2011). Grietas en el silencio. Una investigación sobre la violencia sexual en el marco del terrorismo de Estado, Rosario, Cladem.

Bacci, C.; Capurro Robles, M., Oberti, A.\&Skura, S. (2012), Y nadie quería saber. Relatos sobre violencia contra las mujeres en el terrorismo de Estado en Argentina, Buenos Aires: Memoria Abierta.

Balardini L., Oberlin A.\& Sobredo L. (2010).Violencia de género y abusos sexuales en los centros clandestinos de detención. Un aporte a la comprensión de la experiencia argentina. Buenos Aires: CELS.

Bretal, E. (2016). Rasgos de la cotidianeidad en la 'época de los militares': representaciones de ex-obreros que no estaban metidos en nada. En: Actas de las VII Jornadas de Trabajo sobre Trabajo Reciente. Facultad de Humanidades y Ciencias de la Educación. Universidad Nacional de La Plata. Recuperado de: http://historiapo litica.com/datos/biblioteca/dictaduraactitudes_bretal.pdf

Calveiro, P. (1998). Poder y desaparición. Buenos Aires: Colihue.

Carassai, S. (2013). Los años setenta de la gente común. La naturalización de la violencia. Buenos Aires: Siglo XXI.

Caviglia; M. (2006). Dictadura, vida cotidiana y clases medias. Una sociedad fracturada. Buenos Aires: Prometeo.

Comisión Nacional sobre la Desaparición de Personas (1984). Nunca Más. Buenos Aires: EUDEBA.

Corradi, J. (1996 [1982-83]). El método de destrucción. El terror en la Argentina. En: Quiroga, H.; Tcach, C. (Comp.) (2015), A veinte años del golpe. Con memoria democrática, Rosario: Homo Sapiens. 
D'Antonio, D. (2016a) Género y resistencias en la prisión política durante la última dictadura. En Águila, G; Garaño, S \& Scatizza, P. (Comp). Represión estatal y violencia paraestatal en la historia reciente argentina. Nuevos abordajes a 40 años del golpe de Estado. Facultad de Humanidades y Ciencias de la Educación, Universidad Nacional de La Plata.

D’ Antonio, D. (2016b). La prisión en los años 70. Historia, género y política. Buenos Aires: Biblos.

Di Tella, A. (1999). La vida privada en los campos de concentración. En Devoto, F\& Madero, M. (Comp.). Historia de la vida privada en la Argentina (Vol. III, p. 79 -105), Buenos Aires: Taurus.

Fleury, B\& Walter J. (Compiladores) (2011), Memorias de la piedra. Ensayos en torno a lugares de detención y masacre, Buenos Aires: Ejercitar Memoria Editores.

Foucault M. (2007). Nacimiento de la Biopolítica. En Curso en el Collége de France(1978-1979), Traducción al castellano de Horacio Pons, Buenos Aires: FCE S.A.

Garaño, S. (2010). El "tratamiento" penitenciario y su dimensión productiva de identidades entre los presos políticos (1974- 1983). En Iberoamericana, № 40. Buenos Aires.

Guglielmucci, A (2009). De centro clandestino de detención “Olimpo" a "Sitio de memoria”: reflexiones sobre gestión política y trabajo simbólico. En Birle P., Carnovale V. \& Schindel E. (Eds.) Memorias urbanas en diálogo: Berlín y Buenos Aires, Buenos Aires: Buenos Libros.

Heller, A. (1987). Sociología de la vida cotidiana. Barcelona: Península

Kahan, E. (2011). Entre la aceptación y el distanciamiento: Actitudes sociales, posicionamientos y memoria de la experiencia judía durante la última dictadura militar (1976-1983). Tesis de posgrado en Historia. Universidad Nacional de La Plata. Facultad de Humanidades y Ciencias de la Educación, La Plata, Argentina.

Levín, F. (2008). Arqueología de la memoria. Algunas reflexiones a propósito de Los Vecinos del horror. Los otros testigos. En La historia reciente como desafio a la investigación y pensamiento en Ciencias Sociales. Buenos Aires, CAICYT-CONICET. Recuperado de: https://www.riehr.com.ar/archivos/Investigacion/Dossier\%20Levin\% 20(revisado).pdf

Lvovich, D. (2017). Vida cotidiana y dictadura militar en la Argentina: un balance historiográfico. En Estudios IberoAmericanos, Pontifícia Universidade Católica do Rio Grande do Sul, Porto Alegre, Brasil, Vol. 43 ( $\mathrm{N}^{\circ} 2$ ). Recuperado de: http://revistaseletronicas.pucrs.br/ojs/index.php/iberoamericana/article/viewFile/25184/156 21

Mendizábal, M.; Méndez, M.; Portos, J.; Korzin, A.; Cerruti, I. \& López, M. (2012). El afuera de un centro clandestino de detención: las memorias de los vecinos del "Olimpo". En Topografias conflictivas: memorias, espacios y ciudades en disputa, 1ra. Ed., Buenos Aires: Nueva Trilce. Recuperado de: http://exccdolimpo.org.ar/images/pdf/El-afu era-de-un-centro-clandestino-de-detencion.pdf

Mendizábal, M. \& Portos, J. (2014). Eso que no pudieron destruir. La (re) inscripción de las historias de vida de los detenidos-desaparecidos en el sitio de memoria ex-CCDTyE "Olimpo". Equipo del Programa para la recuperación de la Memoria Histórica sobre el ex CCDTyE "Olimpo", Buenos Aires. Recuperado de: http://exccd olimpo.org.ar/images/pdf/ESO-QUE-NO-PUDIERON-DESTRUIR.pdf

Messina, L. (2008). "El circuito represivo "Atlético- Banco- Olimpo": ¿Distintas sedes de un mismo centro clandestino de detención?”. V Jornadas de Sociología, UNLP- FHCEd (Ed.), Departamento de Sociología, La Plata. Recuperado de: https://www.aacademica.org/000-096/53.pdf

Messina, L. (2010), Politicas de la memoria y construcción de memoria social: acontecimientos, actores y marcas de lugar. El caso del excentro clandestino de detención "Olimpo"(tesis doctoral), Tesis de doctorado en Antropología, Facultad de Filosofía y Letras-UBA, Buenos Aires, Argentina.

Novaro, M. \& Palermo, V. (2003). La dictadura militar (1976-1983). Del golpe de estado a la restauración democrática. Buenos Aires: Paidós.

O' Donnell, G. (1984), Democracia en la Argentina. Micro y macro. En: Oszlak, O. (Comp.). "Proceso", crisis y transición democrática. Buenos Aires: Centro Editor de América Latina.

Rafecas, D. (2005). Resolución en la causa 14.216/03 "Suárez Mason, Carlos y Otros”. Buenos Aires.

Scott, J. (2004). Los dominados y el arte de la resistencia. Discursos ocultos. México: Era. 
Todorov, T. (1993). Frente al límite. México: Siglo XXI.

Vecchioli, V. (2013). Las Víctimas del Terrorismo de Estado y la gestión del pasado reciente en la Argentina. En Papeles del CEIC, Vol.: 2013/1 (No 90), (ISSN: 1695-6494). Recuperado de: http://www.ehu.eus/ojs/index.php/pa pelesCEIC/article/view/12393/11315.

Villani, M. (2011). Desaparecido. Memorias de un Cautiverio. Club Atlético, El Banco, El Olimpo, Pozo de Quilmes y ESMA. Buenos Aires: Biblos.

\section{Fuentes:}

Archivo Nacional de la Memoria, 1985, testimonio de Enrique G., Juicio a las Juntas. Archivo Nacional de la Memoria, 1985, testimonio de Graciela T., Juicio a las Juntas. Archivo Nacional de la Memoria, 1985, testimonio de Isabel C., Juicio a las Juntas. Archivo Nacional de la Memoria, 1985, testimonio de Isabel F, Juicio a las Juntas. Archivo Nacional de la Memoria, 1985, testimonio de Jorge B., Juicio a las Juntas. Archivo Nacional de la Memoria, 1985, testimonio de Juan Carlos G., Juicio a las Juntas. Archivo Nacional de la Memoria, 1985, testimonio de Juan G., en Juicio a las Juntas. Archivo Nacional de la Memoria, 1985, testimonio de Julio L., Juicio a las Juntas. Archivo Nacional de la Memoria, 1985, testimonio de Mario V., Juicio a las Juntas. Archivo Nacional de la Memoria, 1985, testimonio de Mónica B., Juicio a las Juntas. Archivo Nacional de la Memoria, 1985, testimonio de Porfirio F., Juicio a las Juntas. Archivo Nacional de la Memoria, 1985, testimonio de Rengel P., Juicio a las Juntas. Archivo Nacional de la Memoria, 1985, testimonio de Susana C., Juicio a las Juntas. Archivo Nacional de la Memoria, 2010, testimonio de Alberto V., Juicio ABO I. Archivo Nacional de la Memoria, 2010, testimonio de Cristina J., Juicio ABO I. Archivo Nacional de la Memoria, 2010, testimonio de Daniel M., Juicio ABO III. Archivo Nacional de la Memoria, 2010, testimonio de Elsa L., Juicio ABO I. Archivo Nacional de la Memoria, 2010, testimonio de Enrique G., Juicio ABO I. Archivo Nacional de la Memoria, 2010, testimonio de Graciela T., Juicio ABO I. Archivo Nacional de la Memoria, 2010, testimonio de Isabel C., Juicio ABO I. Archivo Nacional de la Memoria, 2010, testimonio de Isabel F., Juicio ABO I. Archivo Nacional de la Memoria, 2010, testimonio de Jorge B., Juicio ABO I. Archivo Nacional de la Memoria, 2010, testimonio de Jorge P., Juicio ABO I. Archivo Nacional de la Memoria, 2010, testimonio de Juan G., Juicio ABO I. Archivo Nacional de la Memoria, 2010, testimonio de Juan L., Juicio ABO I. Archivo Nacional de la Memoria, 2010, testimonio de Julio L., Juicio ABO I. Archivo Nacional de la Memoria, 2010, testimonio de Marcia B., Juicio ABO I. Archivo Nacional de la Memoria, 2010, testimonio de Mario B., Juicio ABO I Archivo Nacional de la Memoria, 2010, testimonio de Mónica B., Juicio ABO I. Archivo Nacional de la Memoria, 2010, testimonio de Porfirio F., Juicio ABO I. Archivo Nacional de la Memoria, 2010, testimonio de Rengel P., Juicio ABO I. Archivo Nacional de la Memoria, 2010, testimonio de Susana C., Juicio ABO I. Archivo Nacional de la Memoria, 2010, testimonio de Susana G., Juicio ABO I. Archivo Nacional de la Memoria, 2010, testimonio Jorge T., Juicio ABO I. 
Entrevista personal a Isabel C., Buenos Aires, 27 de septiembre de 2016.

Entrevista personal a Jorge P., Buenos Aires, 17 de octubre de 2015.

Entrevista personal a M.B., Buenos Aires, 13 de diciembre de 2016.

Entrevista personal a N.F., Buenos Aires, 21 de marzo de 2017.

Archivo Nacional de la Memoria, CONADEP, Legajo de Alberto B., 1984.

Archivo Nacional de la Memoria, CONADEP, Legajo de Cristina J., 1984.

Archivo Nacional de la Memoria, CONADEP, Legajo de Daniel R., 1984.

Archivo Nacional de la Memoria, CONADEP, Legajo de Elsa L., 1984.

Archivo Nacional de la Memoria, CONADEP, Legajo de Enrique B., 1984.

Archivo Nacional de la Memoria, CONADEP, Legajo de Enrique G., 1984.

Archivo Nacional de la Memoria, CONADEP, Legajo de Gilberto R., 1984.

Archivo Nacional de la Memoria, CONADEP, Legajo de Graciela T., 1984.

Archivo Nacional de la Memoria, CONADEP, Legajo de Horacio C., 1984.

Archivo Nacional de la Memoria, CONADEP, Legajo de Isabel C., 1984.

Archivo Nacional de la Memoria, CONADEP, Legajo de Isabel F, 1984.

Informe de la Comisión Nacional sobre la Desaparición de Personas, EUDEBA, Buenos Aires, 1984.

Informe Amnistía Internacional, Ennals, Martín, 1979.

Informe de la CIDH, Buenos Aires, 14 de Diciembre de 1979.

\section{Notas}

1 Bajo su jurisdicción operaron también los CCDTyE “Automotores Orletti”, "Pozo de Banfield” y "La Cacha”.

2 "El Olimpo" integra el Circuito Represivo "Atlético-Banco-Olimpo" (A.B.O), elevado a juicio en 2008 por el juez federal Daniel Rafecas. Este juicio se realizó en tres tramos, entre 2009 y 2017.

3 Funcionó entre febrero y diciembre de 1977, en una sede del Servicio de Aprovisionamiento y Talleres de la Policía Federal. A principios de 1978 fue demolido para construir la autopista 25 de Mayo, y los allí detenidos fueron mudados al "Banco".

4 Funcionó entre diciembre de 1977 y agosto de 1978, en la División Cuatrerismo de la Policía de la Provincia de Buenos Aires, partido de La Matanza. Los cautivos fueron mudados al "Olimpo" luego de su desmantelamiento.

5 Calveiro utiliza la denominación de "campos de concentración” para emparentarlos con los engendrados por el régimen nazi en Alemania (1934-1945), si bien advierte que hay diferencias entre éstos.

6 En la jerga represiva significaba tener los ojos vendados.

7 Eufemismo de exterminio en la jerga represiva.

8 Máximo Nicoletti era montonero y fue detenido en la ESMA donde pasó integrar el "ministaff”, colaborando abiertamente con la represión; y luego de su liberación se convirtió en miembro del servicio de inteligencia, e integró junto a ex represores una banda de piratas del asfalto.

9 Por pedido explícito del Archivo Nacional de la Memoria -y con el fin de preservar las identidades- los testimoniantes serán citados con su nombre de pila y la inicial de su apellido.

10 Se utilizarán siglas para referirse a algunos entrevistados, respetando su pedido, a fin de proteger sus identidades.

11 El término "libertad" resulta perturbador a nuestro entender, pues los detenidos luego de retornar definitivamente a sus hogares continuaron estando a disposición del personal represivo por días, meses e incluso hasta 1984.

$12 \mathrm{Al}$ momento de iniciar el traslado, generalmente los represores les hacían creer a los cautivos que serían enviados a "granjas de rehabilitación” para ser posteriormente reinsertados en la sociedad, por lo cual éste instante no resultó particularmente violento y fue vivido en muchos casos con cierto entusiasmo.

13 Llamaremos "vigilancia atenuada" a la fase de control ilegal de los detenidos por parte del dispositivo represivo durante el período posterior al cautiverio, entendiendo por 'vigilancia' al sistema de control periódico y direccionamiento de la voluntad de las víctimas. En cuanto al concepto "atenuada”, el mismo nos sugiere cierta continuidad de las estrategias de sometimiento, aunque atemperadas por no transcurrir ya en un contexto de encierro, ni de sometimiento a torturas físicas. Con ello se pone en tela de juicio la categoría 'libertad vigilada', esgrimida por los represores para denominar esta práctica. 